\title{
Post-Enlightenment Exploration and the Aesthetic of Information: Curious with a Purpose
}

\author{
Diganta Bhattacharya \\ Assistant Professor, Department of English, Sundarvan Mahavidyalaya, West Bengal \& \\ Research Scholar, Presidency University. Email: diganta.bhat@gmail.com
}

\begin{abstract}
:
Exploration accounts written during the post-Enlightenment era of European expansion relied upon the agency of a romanticized narrator who could inspire a dedicated readership since he strategically projected the 'performance' of exploration as necessarily hazardous and hence, awe-inspiring. The concomitant element of romance was further emphasized in such texts since the precarious and vulnerable position of the explorernarrator functioned as a much-needed foil to the sort of objectivist-detached discourse of functional intelligence that exploration narratives were increasingly expected to generate. The elaborate, methodical, organized and professional performance of overseas exploration needs to be understood as a targeted activity that utilized specific narratorial devices with an aim to make use of the widespread curiosity about the New World. This essay seeks to address the post-Enlightenment emergence of an 'aesthetic of information' along with its discursive trappings and epistemological frameworks which were 'realized' within a subculture of geographical exploration. 'Knowledge' aspired to be defined by empirical rigour, but the process of accessing and documenting it could scarcely avoid subjective variables.
\end{abstract}

Keywords: Enlightenment, Exploration, Knowledge, Information, Romantic, Aesthetic, Science, Functional, Empirical, Baconian, Curiosity

\section{The Exploration Account Conceived as a Romance}

Roald Engelbregt Gravning Amundsen, the Norwegian explorer was the first person to reach the South Pole, the first to make a ship voyage through the Northwest Passage ${ }^{i}$ and one of the first to cross the Arctic by air. In one sense Amundsen was the personification and an apotheosis of the hallowed tradition of overseas explorations that started shaping the world and 'modernity' as its idea has been conceived since Magellan's circumnavigation. In his own exploration account to be published in 1908, he remarks:

Oddly enough it was the sufferings that Sir John [Franklin] and his men had to go through which attracted me most in his narrative. A strange urge made me wish that I too would go through the same thing. (as cited in Flaherty, p. 27)

This John Franklin is of course Rear-Admiral Sir John Franklin (16 April 1786 - 11 June 1847), English Royal Navy officer and Arctic explorer who was lost in an ambitious exploration off the west coast of Greenland, in the midst of the profusion of islands coupled with confusing waterways that characterizes the then-unmapped Canadian Arctic Archipelago and then declared deceased after years of searching. But this autobiographical observation demonstrates two specific features that have remained rather typical across almost every European exploration narrative written since the

(C) AesthetixMS 2021. This Open Access article is published under a Creative Commons Attribution Non-Commercial 4.0 International License (http://creativecommons.org/licenses/by-nc/4.o/), which permits non-commercial re-use, distribution, and reproduction in any medium, provided the original work is properly cited. For citation use the DOI. For commercial re-use, please contact editor@rupkatha.com. 
150o's: a) the explorer-narrator drawing his 'inspiration' from chief acts of explorations that have happened so far or more appropriately, from the textual accounts of those voyages, and b) a young mind hungry for glory and recognition, easily susceptible to romantic reimagining-s of travel that could not be esteemed without components of travail, and the consequent idealization of exploration as an arduous task that consisted of putting oneself amidst dangerous circumstances and potentially hazardous situations. Interestingly, Amundsen immediately qualifies this observation by a statement that reads: "Perhaps it was the idealism of youth, which often takes the form of martyrdom, that got me to see myself as a kind of crusader in Arctic exploration." (Flaherty, p. 28)

This component of romance, along with the concomitant feelings of wonder contributed to the selfdramatization of the explorer-narrator and it had curious ramifications in the way the exploring self has been represented by and through the narrating self. Customarily this choice is explained as part of the overall 'agenda' of the narrator, a scheme that involves devices meant to address potentially problematic areas ranging from manipulating as well as structuring the readers' appreciation of the text(s) to registering a definitive ethno-cultural standpoint. Pratt has demonstrated how an obsessive preoccupation with the narratorial-exploring self has been sequentially maintained through passages that record a disquieting amount of reference to the narrating 'I' by means of dramatization and victimization of the self (pp. 74-75). Due to the 'placing' of the self as the receiver, as the focal point of a centripetal structure of happenstances where everything is in a sense geared towards the one who experiences, writes and edits, the explorer's self-construction is almost always accompanied with romanticized ideas of what exploration justifiably entails. Exploration and its narrativization, to that extent, becomes an anticipatory process of filling-in as the composite project aspires to live up to generic and established expectations of what it means to be an explorer.

\section{The Exploration Account Conceived as a Strategic Discourse}

As one looks at the trajectory of the evolution of exploration narratives during the postEnlightenment era of rapid expansion, one is aware of a precarious compromise achieved among three principal factors which were responsible for three differently-oriented texts: a travelogue that was calculated to create a sense of wonder and bewilderment, a self-dramatizing narrative that foregrounds the explorer-narrator as braving apparently insurmountable odds, and a more functionally-driven topographical account that increasingly emphasized the information-content along with its use-value. The 'aesthetics of travel', hence, has never been an undifferentiated, unaltered modality of accessing the subjective dimension of travel-experience and its textualization: the concept, as indefinite and abstract as it may sound, has undergone steady yet predictable changes since the post-Renaissance 'conceptual opening' and the Enlightenment philosophy of knowledge which was attendant upon this cognitive shift. Premium European institutions of knowledge-generation found themselves entangled in a mutual rivalry of discovering more secrets that natural world offered, as is evident by the way both the Royal Society of England and Académie des Sciences of France sent contending delegations to map the famous Transit of Venus that happened in $1769 .{ }^{\text {ii }}$ This scramble for gaining the sort of objective, empirical, functional knowledge that such an astronomical 'tracking' promised, could only be ensured through rigorous expenditure of energy, human resources and extensive fieldwork. The insistence on the need to gather useful data can be attributed to the Enlightenment ambition of accessing the hidden laws of a deterministic nature with predictable, inviolable, and most importantly, intelligible parameters. There is discernible a discursive re-appropriation of something that was hitherto conceived as 
essentially academic: a remapping of the tools of knowledge-gathering to incorporate the aspirations of a nascent empire. Every European nation at the forefront of maritime and (later) industrial capabilities had its individual perception of 'revealed destiny' that promised greatness only if the hitherto-unexploited reservoir of scientific-geographical information could be effectively tapped. This act of 'effective tapping' implied accessing and exploiting specific itineraries that received institutional validation and became more technical, professional and hence demanding. Items or specimens needed to be collected, analyzed, sorted out, arranged, tagged and displayed in what Paul Smethurst has referred to as "the museum order" (p. 16). It is precisely this elaborate-tothe-point-of-being-ritualized framework of 'scientific operation' that Latour refers to as the cycle of accumulation, a totalizing device of discursive penetration that could only be realized through textual strategies:

If we define knowledge as familiarity with events, places and people seen many times over, then the foreigner will always be the weakest of all except if, by some extraordinary means, whatever happens to him happens at least twice; if the islands he has never landed at before have already been seen and carefully studied, as was the case with the navigator of the Neptuna, then, and only then, the moving foreigner might become stronger than the local people. What could these 'extraordinary means' be? ... he will gain an edge only if the other navigators have found a way to bring the lands back with them in such a manner that he will see Sakhalin island, for the first time, at leisure, in his own home, or in the Admiralty office, while smoking his pipe .... As we see, what is called 'knowledge' cannot be defined without understanding what gaining knowledge means. In other words, 'knowledge' is not something that could be described by itself or by opposition to 'ignorance' or to 'belief, but only by considering a whole cycle of accumulation: how to bring things back to a place for someone to see it for the first time so that others might be sent again to bring other things back. How to be familiar with things, people and events, which are distant." (Latour, pp. 229-30)

What Latour has demonstrated here is the way knowledge is intricately enmeshed in the networks of specific and established sets of behavioural practices and that knowledge, hence, is a functional concept with a more-or-less firmly recognized modalities of engagement. It implies a teleological development, a chronological, incremental orthogenesis in terms of both discursive construction and an attendant behavioural aspect that undergoes predictable changes and transitions as the episteme inevitably responds differently to constantly-altering societal demands. This 'take' on the structural aspect of the formation of the body-of-knowledge is essentially Foucauldian in the way a network of interrelatedness is supposed to always locate the discursive practice of informationgeneration within the contingencies of history:

If one recognizes in science only the linear accumulation of truths or the orthogenesis of reason, and fails to recognize in it a discursive practice that has its own levels, its own thresholds, its own various ruptures, one can describe only a single historical division... All the density of the disconnexions, the dispersion of the ruptures, the shifts in their effects, the play of the interdependence are reduced to the monotonous act of an endlessly repeated foundation. (Foucault, p. 188)

But Latour's analysis seeks to contextualize this with references that are relevant to the present argument. As an organized and planned-out activity, exploration, more specifically during the centuries of the European expansion, was a goal-oriented affair that demanded spatial movement and the paraphernalia of logistical preparedness that inevitably accompanied such a project. Exploration was after all travelling with a specific set of agenda that are realized by a combination 
of diverse format-s of travel available to the aspirant explorer after the $17^{\text {th }}$ century; neatly categorized by Judith Adler as 'romantic', 'picturesque', 'philosophical', 'curious', and 'sentimental' (p. 1372). The panoply of styles (Adler, p. 1371) that such a diversified scheme warrants, further complicated by the inescapable variations of individual perspectives, naturally render the task of 'working out' one unmistakable stylistic framework quite near-impossible. Narratorial conventions either changed or underwent significant modifications as the ostensible purpose of exploration changed, along with the steadily updating modalities and techniques of knowledge-gathering. Under such circumstances, from a functional point of view such an intricate performance becomes an elaborate enactment of a set programme, a gradual unfolding of a carefully-wrapped package as it were; and it is in this performative context that the semantically overburdened word 'exploration' begins to make sense. This is so because comprehensive analyses of exploration-performance help one in cognizing the structural aspects of it, understanding the causal relations that span the mindbogglingly diverse and extensive framework of negotiations and engagements that doesn't only constitute that act of exploration, but is, in a way, exploration itself. It is in this sense that Latour's conceptualizations are so pivotal. The overarching idea of the empire that spanned oceans and continental distances was firmly predicated upon a presupposition of exchange that could be possible only through a gradual widening of informational pathways. 'Knowing' the distant was not only a matter of cultivating the much-theorized emotional responses of curiosity and wonder; it was something tangible in essence, as it is through knowledge garnered and organized that the idea of exchange that constituted the substratum of colonial expansion could be realized. An exploration account or a travel narrative written during this period of geographical expansion, then, employed an aesthetic of information to remain contextual for two different groups of people who consumed such texts: the 'common' public with an insatiable hunger for the strange, the different, the distant and those that sought to exploit the informational content of such texts.

\section{Post-Enlightenment Reconfiguration of Knowledge and Scramble for Information}

The 'what', 'why' and 'how' of any statement constitute the discursive bulwark against which the technical acceptability of such a statement is assessed. Categorical stress on these semantic markers characterized travel and exploration narratives written during this timeframe, and in an unmistakable way this emphasis on specific questions and their objective-descriptive framework can be traced in Enlightenment reasoning and its insistence on the possibility of establishing a neatly ordered and meticulously structured idea of nature and reality. This aspiration, during the British Enlightenment, was more significant and multi-dimensional than a gradual increase in the acceptability of the Baconian ideas of knowledge and its parameters might suggest. As 'science' gradually and inevitably underwent a transition that sought to establish itself as an organized, institutional activity to render it more effective, the process dearly needed, as Bacon rigorously maintained, methodical categorization, objective professionalism and precisely-demarcated disciplinary divides. But the word 'science' was already a loaded signifier with its connotation not necessarily restricted to the cognitive parlance: it traditionally meant a specific system of knowledge based on general truths and laws obtained and tested through particular method, yet simultaneously it also encapsulated traditional ideas of a socially embedded practice. What was therefore at stake was more than a modality of knowledge-accumulation and dissemination; - the ethical concepts of civility, truth, trust, honour and integrity were also conceived to be an elaborate codex of what 'science' should ideally be. In fact, the idea that as an inescapably cooperative endeavour with substantial social impact 'science' needs to be construed in terms of ethical accountability (as opposed to a completely objective, hence value-free activity) was not new and is 
increasingly gaining widespread acceptance both outside of and within the academia. Science as a methodological discourse of information cannot but rely upon, specifically for all its neat categorizations to work as expected, a 'division of linguistic labour' which is only possible in an atmosphere of verbal cooperation; a linguistic paradigm in which orthographic and semantic vagueness can only be circumvented through a voluntary participation in a mutually-agreed upon system. The seemingly objective requirement of remaining 'detached' in a way that implies a valuefree perspective, then, becomes a contentious moral choice with far-reaching implications for how the conjoined issues of 'scientific' ontology and epistemology need to be understood. iii This idea is further elaborated by Rorty as he explains how the collaborative nature of science demonstrates firmly entrenched, yet too-often-overlooked ethical dimensions:

Another meaning for 'rational' is, in fact, available. In this sense, the word means something like 'sane' or 'reasonable' rather than 'methodical'. It names a set of moral virtues: tolerance, respect for the opinions of those around one, willingness to listen, reliance on persuasion rather than force. These are the virtues which members of a civilized society must possess if the society is to endure. In this sense of 'rational', the word means something more like 'civilized' than like 'methodical' ...On this construction, to be rational is simply to discuss any topic- religious, literary, or scientific- in a way which eschews dogmatism, defensiveness, and righteous indignation. (Rorty, p. 36)

In any case, it was chiefly from the Enlightenment that the predominantly medieval idea of the scholar as one deeply enmeshed in his study, oblivious of the reality around, reveling in hermetic seclusion and metaphysical abstractions could no longer be appropriated to refer to the 'scientists' precisely because of these presuppositions regarding their macrosociological participations and discursive affiliations. With respect to overseas forays into barely-known corners of the planet, the cartographic widening of the oikumene ${ }^{\text {iv }}$ couldn't help being accompanied by its ontological counterpart when it concerned the sciences: there were simply more things to know. When Sir Walter Raleigh observes, “...our own experience had taught us, that there are stranger things to be seen in the world than are contained between London and Staines" (Cited in Shapin, p. 19), the sentiment expressed may be strangely reminiscent of Hamlet's assurance of there being 'more things' than could even be 'dreamt of in the philosophy; but that was the chief preoccupation of any inquisitive mind during the Enlightenment rise of the empirical sciences. Every bit of technical, professional and functional knowledge deserved to be codified and included in a systematized discourse of information that could be, most importantly, utilized. Factual knowledge was tantamount to information that was capable of producing specific results in a visible and testable manner and it is for this that the hitherto-uncategorized and largely undocumented informationcontent circulating among specific professions like potters, alchemists, miners, hydrographers ${ }^{\mathrm{v}}$ and the like was hailed as harboring ontological promises that ensnared minds which were convinced about an illustrious future for knowledge-with-purpose. A thorough dismantling of the previous hierarchization of knowledge-scheme was inevitably accompanied with a miscellaneous inquisitiveness that assured realistic dividends. For this vision to be realized, abstract knowledge of logical deductions that followed close observation of natural phenomena needed to be complemented by strides in technical expertise that could actualize those possibilities. Paolo Rossi's analysis captures this inclination towards academic endorsement of the 'practical' along with the theoretical:

This new interest in technical and mechanical methods, based on a belief in their educative powers, is typical of the sixteenth and seventeenth centuries. The accomplishments of artisan, engineer, technician, navigator, and inventor were considered of equal importance 
to intellectual achievements, and Bacon, Galileo, and Harvey, among others, explicitly acknowledged their debt to the artisan... Sciences such as chemistry, mineralogy, botany, and geology thrived on the fusion of scientific and technical knowledge. Another consequence of the new status of technology and its methodological procedures was the realisation that theories should be tested before they could be accepted, and the lack of connection between traditional scientific learning and the practical potentialities of science was set in evidence by-an increased familiarity with the mechanical arts. (pp. 1-2)

The entire framework of ancient knowledge could not so easily be dismantled though; the infusion of techne and praxis might have satisfied those with a keen eye on the dictum of 'knowledge-withpurpose', but such an ontological shift still awaited the greatest challenge of all- test of time, as Bacon had unambiguously observed: "For truth is likely called the daughter of time, not of authority" (The New Organon, p. 69). Drawing conclusions too hurriedly and too frequently seemed dangerously reckless to even one like Montaigne:

It is foolish presumption to go around disdaining and condemning as false whatever does not seem likely to us; which is an ordinary vice in those who think they have more than common ability...We must judge with more reverence the infinite power of nature, and with more consciousness of our ignorance and weakness. (pp. 132-33)

The choice of accepting the ancient with uncritical reverence could no longer be regarded a viable option at all, but nor could that of spurning it with condescension as disregard for the much-needed temporal validation that also connoted social acceptance could only result in epistemic errors:

So it seemeth men doubt lest time is become past children and generation; wherein contrariwise we see commonly the levity and unconstancy of men's judgments, which, till a matter be done, wonder that it can be done; and as soon as it is done, wonder again that it was no sooner done...But in intellectual matters it is much more common, as may be seen in most of the propositions of Euclid; which till they be demonstrate, they seem strange to our assent; but being demonstrate, our mind accepteth of them by a kind of relation (as the lawyers speak), as if we had known them before. (Bacon, Advancement of Learning, p. 36)

This called for a difficult balance between assumed, inherited parameters of knowledge and the ever-growing lure for newer and stranger fields of knowledge that apparently held more 'promise'. Texts on exploration and overseas travels written during this period assumed a crucial role in this regard; it is through these texts that there began a gradual widening of the horizon of expectations about what was possible to know. It is no wonder, therefore, that references to such exploits recurred in formal disquisitions on knowledge. Bacon eulogized the value of explorations and the consequent broadening of conceptual boundaries that had a palpable effect on contemporary intellectual environment:

We should also take into account that many things in nature have come to light and been discovered as a result of long voyages and travels (which have been more frequent in our time), and they are capable of shedding new light in philosophy. Indeed it would be a disgrace to mankind if wide areas of the physical globe, of land, sea and stars, have been opened up and explored in our time while the boundaries of the intellectual globe were confined to the discoveries and narrow limits of the ancients. (The New Organon, P. 69)

In a similar vein in 1638 Bishop John Wilkins (1614-1672), the Oxford-educated Chaplain who was also a well-known advocate of the Baconian system of knowledge, argued that every new idea, like that of the Antipodes, was likely to be greeted by substantial amount of suspicion and scorn because 
of the element of 'novelty' involved; but the proper course of action is that it should be subjected to 'diligent enquiry' as every idea should ideally be:

...but the same Novelty which is esteemed the commendation of errour and makes that acceptable, is counted the fault of truth, and causes that to bee rejected. How did the incredulous world gaze at Columbus when hee promised to discover another part of the earth, and he could not for a long time by his confidence, or arguments, induce any of the Christian princes, either to assent unto his opinion, or goe to the charges of experiment...it hath alwaies beene the unhappinesse of new truths in Philosophy, to be derided by those that are ignorant of the causes of things, and reiected by others whose perversenesse ties them to the contrary opinion, men whose envious pride will not allow any new thing for truth which they themselves were not the first inventors of... That a new truth may seeme absurd and impossible not onely to the vulgar, but to those also who are otherwise wise men, and excellent schollers; and hence it will follow, that every new thing which seemes to oppose common Principles is not presently to be rejected, but rather to be pry'd into with a diligent enquiry, since there are many things which are yet hid from us, and reserv'd for future discovery. (pp. 8-9 \& 15)

\section{(Inter)personal Variables and the Impossibility of Absolute Objectivism}

Exploration and travel, therefore, existed within a network of references that accrued significance as it continued to be used as metaphors for a number of ideas associated with knowledge and its transformative aspect: the arduous intellectual journey, an enterprise that demanded commitment and sacrifice, unprecedented widening of conceptual boundaries and the psychological preparedness to accept the hitherto unthinkable, specific methodological approaches that ensured the 'demonstrable' content of a claim, thereby maintaining the requirement for empirical validation and so on. The spate of explorations that roughly began with Columbus is categorically different from those that preceded them because they are characterized by a functional ratification of the new systems of knowledge-production and dissemination. The exploration-events provided functional justification for methods and systems that had already received theoretical endorsement from those responsible for the drafting of engagement-policies that were to be followed. The Royal Society, founded in 1660 and granted a special royal charter ${ }^{\text {vi }}$ from Charles II in 1662, proclaimed to follow the dictum of nullius in verba ${ }^{\text {vii }}$ which was supposed to connote a vehement, uncompromising reliance on empiricism and factual veracity. But as has already been briefly pointed out, in a confused discursive field that sought to amalgamate preexisting frameworks of cognizing the reality along with newer, stranger and constantly-updated cognitive modules, 'science' encompassed socio-cultural connotations as well as assumptions that are far more fluid and undefinable than a committed empiricist might prefer. It was due to this confluence of different modalities of 'assessing' truth that something as supposedly nomothetic as evaluating a physical experiment was not indubitable: as a case in point Robert Hooke (1635-1702), the renowned natural philosopher and a fellow of the Royal Society admitted the empirical worth of Newton's theories of optics but flagrantly denied the inferences with the claim that Newton's methods of experimentation were inconclusive. Newton, consequently, as Alan E. Shapiro has pointed out in his detailed study, had to contend with the complications related to his ideas concerning inductive constitution of universal truth, the 'evident-ness of sensory experience' and the precise nature of experimentum crucis (pp. 211-235).

Moreover, the fundamental framework of reference and proof that the truth claims of exploration journals relied upon, namely, objective and eyewitness accounts and 'personal' experiences, 
couldn't be accepted as unassailable and adequately empirical as those 'commentaries' changed from one person to another, owing to inescapable differences in perceiving the same phenomena. Georg Forster ${ }^{\text {viii }}$ pertinently observes as he recalls how his 'occupation' was different from Cook's as the ship anchored in a foreign land and he went to take a stroll near the harbour "...in quest of the manifold objects which Nature had scattered throughout the land" (p. 7) while Cook remained busy in victualling the ship:

Nothing is therefore more obvious, than that each of us may have caught many distinct incidents, and ... our observations will frequently be foreign to each other. But above all, it is to be observed, that the same objects may have been seen in different points of view, and that the same fact may often have given rise to different ideas ... the different branches of science which we have studied, our turns of mind, our heads and hearts have made such a difference in our sensations, reflections, and expressions." (Ibid)

This observation is significant as it represents not only the heightened awareness of a single rational adventurer-turned-travel writer; it also underscores a conscious admission of the inconsistency inherent in a rigorous empirical framework that excludes interpersonal variables. The realization of the intrinsically provisional nature of an elaborate, strategic act of observation which is followed by writing about the way it was 'performed' by one single individual, dented a Newtonian-Cartesian faith in sense-empiricism and made people aware of the intricate but unavoidable issues of perspectivism and subjective biases. This, in turn, restored the elements of a subjective sense of wonder and bewilderment and bemused amazement at the sight of the 'different', -all of which appeared irrevocably lost with the sudden onslaught of inflexible, precise, and most importantly, generalizable laws and their apparent predictive capabilities. The element of astonishment, of curious wonder which was "...the decisive emotional and intellectual experience in the presence of radical difference" (Greenblatt, p. 14), is key to the entire exploration-framework as it sought to guarantee that the interest of both the academia as well as the common people never flagged. This, in turn, ensured that newer overseas endeavours continued to receive financial and logistical assistance.

\section{Notes}

i The sea route to the Pacific Ocean through the Arctic Ocean, a route that consists of a series of deep channels through Canada's Arctic Archipelago, is riddled with thousands of icebergs of different shapes and sizes.

It is roughly in this patch of frozen land-water confluence that the infamous iceberg that sunk the Titanic had started its fateful journey about three thousand years ago as it is estimated that during any 5-year tenure in the two decades (1901-1920) approximately 700 icebergs broke away from this region and crossed the $48^{\circ} \mathrm{N}$. (Bigg \& Wilton, pp. 102-104)

ii The transit of Venus was indeed a very rare phenomenon that sought to resolve a nagging astronomic problem: the precise calculation of the distance between the sun and earth, something that would in turn would serve as a unit for the measurement of the universe itself, as suggested by Kepler.

The transit of 1761 and 1769 had gained a sort of added importance much before, when an exceedingly popular man of science like Edmond Halley was speaking of this enormously significant eighteenth-century cosmic event as he addressed the Royal Society in 1716, knowing that he, who was born in 1656, could do nothing but prophesy, exhort, and encourage.

iii For more on this, see Putnam, pp. 131-193. 
iv This word is used to imply the extent of the 'known world'; the entirety of the planet that had been cartographically organized so far.

v Hydrography, a highly technical area of expertise still exists and employs scholars of Geology and Mathematics and those who can make sense of satellite data. But about 400 years ago this was obviously not the case. A hydrographer was expected to draw a usable map of the coasts, measure the type and depth of water as the ship coursed through it and was an important official in an exploration-contingent. The Dutch hydrographers were immensely successful in the beginning, followed by the French, a reality that Samuel Pepys (1633-1703) lamented and sought to redress the situation by instigating the Admiralty to allot more resources so that the regrettable dependence on Dutch and French accomplishments could be diminished. It was not before 1795, however, that the Admiralty took a definitive step in recruiting Alexander Dalrymple as Hydrographer to the Board of Admiralty, whilst retaining his post for a time with the East India Company, after his apparent successes as a hydrographer for his effective chart-making in the Far East in the 1779. For a concise yet informative account of the history of Hydrography in the Europe, consult Ritchie, pp. 7-20.

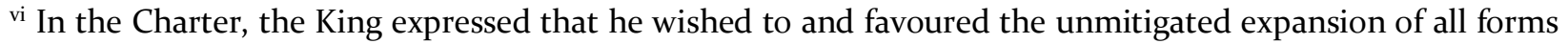
of learning - the arts and the sciences—so that such intellectual refinement might influence the entirety of 'the Empire'. But there was a perceivable preference for the 'experiment philosophy', or 'natural philosophy' which was another phrase for Science.

vii Literally meaning 'on the word of no one' or 'take nobody's word for it'; - this is actually a paraphrased excerpt of sorts from Horace's Epistles and originally it was intended to imply liberation from a master or a school (of thought).

viii Georg Forster (1754-1794) was a German naturalist, ethnologist, travel writer, journalist, and revolutionary who accompanied James Cook in his second voyage to the Pacific. His A Voyage Round the World (first published in 1777) earned him a place in the Royal Society at a young age and he is hailed as one of the pioneers who developed 'scientific' travel narrative.

\section{References:}

Adler, Judith. (May, 1989). “Travel as Performed Art”. The American Journal of Sociology. Vol. 94, No. 6.

Bacon, Francis. (2008). Bacon's Advancement of Learning and the New Atlantis. Oxford, Benediction Classics.

Bacon, Francis. (2000). The New Organon. Ed. Lisa Jardine. Cambridge University Press.

Bigg, Grant R. and Wilton, David J. (2014). “Iceberg risk in the Titanic year of 1912: was it exceptional?". Royal Meteorological Society. Retrieved From https://doi.org/10.1002/wea.2238

Montaigne, Michel de. (1965). The Complete Essays of Montaigne. Trans. Donald Murdoch Frame. Stanford University Press.

Greenblatt, Stephen. (1988). Marvelous Possessions. Clarendon Press.

Flaherty, Leo. (1992). Roald Amundsen and the Quest for the South Pole. Chelsea House Publishers.

Forster, Georg. (2000). A Voyage Round the World, Volume 1. Eds. Nicholas Thomas and Oliver Berghof. University of Hawaii Press.

Foucault, Michel. (1972). Archaeology of Knowledge. Trans. A. M. Sheridan Smith. Pantheon Books.

Latour, Bruno. (1988). Science in Action: How to Follow Scientists and Engineers. Reprint. Harvard University Press.

Putnam, Hilary. (1975). “The Meaning of 'Meaning”. Language, mind, and knowledge: Minnesota Studies in the Philosophy of Science, Volume 7. Ed. Keith Gunderson. University of Minnesota Press. 
Ritchie, G.S. (January 1991). “The History of Hydrography: An Enlightened European Era 1660-180o”. International Hydrographic Review, 68(1). Retrieved From https://journals.lib.unb.ca/index.php/ihr/article/view/23283

Rorty, Richard. (1990). "Science as Solidarity”. Objectivity, Relativism, and Truth: Philosophical Papers, Volume 1, Cambridge University Press.

Rossi, Paolo. (2013). Francis Bacon: From Magic to Science. Routledge.

Shapin, Steven. (2018). The Scientific Revolution. University of Chicago Press.

Shapiro, Alan E. (1980). "The Evolving Structure of Newton's Theory of White Light and Color". Isis, 71(2). DOI: $10.1086 / 352461$

Smethurst, Paul. (2012). Travel Writing and the Natural World, 1768-1840. Palgrave Macmillan.

Wilkins, John. (1638). The Discovery of a World in the Moone, E.G. for Michael Sparke and Edward Forrest. Boston Public Library. Retrieved From

https://archive.org/details/discoveryofworldoowilk/page/ng/mode/2up 